\title{
GIANT DUMBBELL HYDATID CYST
}

Rahul Bhargava ${ }^{1}$, Pradeep Soni², Atul Manoharrao Deshkar ${ }^{3}$

\section{HOW TO CITE THIS ARTICLE:}

Rahul Bhargava, Pradeep Soni, Atul Manoharrao Deshkar. "Giant Dumbbell Hydatid Cyst". Journal of Evolution of Medical and Dental Sciences 2014; Vol. 3, Issue 23, June 09; Page: 6273-6276,

DOI: $10.14260 /$ jemds/2014/2734

\begin{abstract}
Hydatid disease is a parasitic infection caused by cestode Echinoccus. It is seen more commonly in countries where agriculture and stalk breeding is widespread. It has remained an important health issue in the underdeveloped world. A case report of a relatively uncommon presentation of recurrence is presented. We describe an unusual case of a recurrent Giant Hydatid Cyst, with recurrence in the abdomen (lesser sac) and growing into the left thorax via the hiatus taking the shape of a dumbbell hydatid cyst in an 18 years old girl, reported to our hospital with complaints of non-resolving cough for 3 months, pain in the chest left side and fever on and off. The treatment options for the hydatid cyst depend on stage, localization, size and complications of the cysts and include operative and non-operative methods. When used alone, chemotherapy with anti helminthics of benzimidazole family has a limited efficacy, mostly related to the accessibility of the drug into the cyst. This treatment option is better when used as an adjunct to surgery to prevent recurrence.
\end{abstract}

KEYWORDS: Hydatid cyst, dumbbell.

INTRODUCTION: Hydatid disease has been well-known since the time of Hippocrates. Hydatid disease is a parasitic infection caused by cestode Echinoccus. It is transmitted to humans via domestic carnivores and has a worldwide distribution. It is seen more commonly in countries where agriculture and stalk breeding is widespread. It has remained an important health issue in the underdeveloped world.

The liver (50-75\%) and the lungs (10-30\%) are the primary organs involved. Involvement of the heart, kidneys, spleen, brain, thyroid and other organs such as muscles (1-5\%) is rare. A definitive diagnosis requires a combination of imaging; serology and immunological study along with clinical examination and of course a proper history. However, a hydatid cyst in an unusual site or of an unusual size may complicate the differential diagnosis.

Large cysts, called Giant Hydatid Cysts are rare even in endemic areas,. These Giant Hydatid Cysts have an exophytic growth through natural routes anatomically. We describe an unusual case of a recurrent Giant Hydatid Cyst, with recurrence in the abdomen (lesser sac) and growing into the left thorax via the hiatus taking the shape of a dumbbell hydatid cyst.

CASE REPORT: An 18 years old girl reported to our hospital with complaints of non-resolving cough for 3 months, pain in the left side chest and fever on and off. Chest X-ray showed encysted collection in the left side chest. On needle aspiration small amount of clear fluid $(2-5 \mathrm{ml})$ was tapped The patient had a history of undergoing a surgical intervention for abdominal hydatid disease 10 years back at the age of 8 years, followed by a course of medical treatment for three months.(scar mark present in the epigastric region.) 
Routine lab investigations showed raised eosinophil counts. Ultrasonography of the abdomen showed a cystic mass with multiple daughter cysts in the lesser sac with extension into the left side thorax.

CECT thorax and abdomen showed features suggestive of a giant hydatid cyst with multiple daughter cysts in the lesser sac in the abdomen and extending into the left side thorax via the hiatus with widening of the hiatus. The patient was kept on anti helmenthic therapy for 3 weeks and was taken up for laparotomy under general anesthesia with selective right sided ventilation. She underwent a complete removal of the intra-abdominal cyst in the lesser sac and the thorax was opened through the diaphragm with the hiatus and the extension of the cyst in the left thorax was also removed in Toto. The hiatus was reconstructed with prolene no.1 and the diaphragm was sutured with prolene no.1 transverse mattress sutures.

Intraoperatively the infected area was lavaged with $20 \% \mathrm{NaCl}$, thrice and an ICTD was placed in the left thorax and an abdominal drain in the abdomen. Post operatively the patient underwent planned chest physiotherapy and breathing exercise and the drains were removed on the $6^{\text {th }}$ day. Once the patient started accepting orally she was placed on anti helmenthic therapy for 13 weeks. The patient is still under follow up without any complaints; relapse or post-operative complications.

DISCUSSION: The primary cause of the hydatid cyst infestation into humans is through ingestion of water or food contaminated by carnivore feces containing embryos.(1) The eggs are opened as they leave the stomach and the developing embryos move through the intestine. Most of them are filtered by the liver however those passing reach the lung where they become lodged. Embryos may directly lodge in the lungs bypassing the liver via the lymphatic. Even if the disease has been treated successfully at one site, the embryos may travel via the blood stream and get lodged at a different site or organ.(2)

Echinococcal cysts are mostly found in the liver (75\%), lungs (15\%) and less frequently at other anatomical sites. (3)

The treatment options for the hydatid cyst depend on stage, localization, size and complications of the cysts and include operative and non-operative methods.(4) Operative methods include classical surgical techniques (total or subtotal cyst-pericystectomy, capsulorraphy, capitonnage, omentoplasty); minimally invasive techniques, such as laparoscopic or robotic procedures; and other treatment modalities such as PAIR with scolicidal solutions. When used alone, chemotherapy with anti helmintics of benzimidazole family has a limited efficacy, mostly related to the accessibility of the drug into the cyst.

This treatment option is better when used as an adjunct to surgery to prevent recurrence.(5) Indications for surgery are active cyst, complicated cyst, cyst near vital organs and giant hydatid cyst, which has a risk of rupture. Radical surgical resection remains the main stay of curative treatment and an accurate pre-operative localization is essential.(6)(7)

In our case, the large dimension of the cyst and its proximity to the vital organs induced us to operate so as to prevent complications such as rupture into the pleural cavity or IVC compression. As for sure the challenge in this case laid in the conspicuity of the Hydatid Disease.

Indeed the case reported here is an extremely rare condition of recurrence of the disease with a giant hydatid cyst originating in the lesser sac and gradually extending through the hiatus into the left hemithorax taking shape of a Dumbbell Hydatid. 


\section{REFERENCES:}

1. Merdivenci A. Hydatid disease in turkey. in: Cerrahpasa Medical School Publications. Istanbul: Istanbul university;1976.p.111

2. Burgos R, Varela A, Castedo E, et al. Pulmonary Hydatidosis: Surgical treatment and follow up of 240 cases. Eur J Cardiothorac Surg 1999;16: 628-35.

3. Turgut AT, Levent A, Sahil T et al: Unusual imaging characteristics of complicated hydatid disease. Eur J Radiol 2007, 63:84-93.Pubmed Abstract|Publisher full text.

4. Craig PS, McManus DP, Lightowlers MW, Chabalgoity JA, Garcia HH, Gavidia CM, Gilman RH, Gonzalez AE, Lorca M, Naquira C, Nieto A, Schantz PM: Prevention and control of cystic echinococcosis. Lancet Infect Dis 2007, 7:385-394. PubMed Abstract Publisher Full Text

5. Crețu CM, Codreanu RR, Mastalier B, Popa LG, Cordoş I, Beuran M, Ianulle DA, Simion $S: A l b e n d a z o l e$ associated to surgery or minimally invasive procedures for hydatid disease how much and how long. Chirurgia (Bucur) 2012, 107(1):15-21.

6. Butterschoen K, Carli Butterschoen C: Echinococcus granulosus infection: the challenge of surgical treatment. Langenbecks Arch Surg 2003, 388:218-230. PubMed Abstract Publisher Full Text.

7. Filippou D, Tselepis D, Filippou G, Papadopoulos V: Advances in liver echinococcosis: diagnosis and treatment. Clin Gastroenterol Hepatol 2007, 5:152-159. PubMed Abstract | Publisher Full Text .

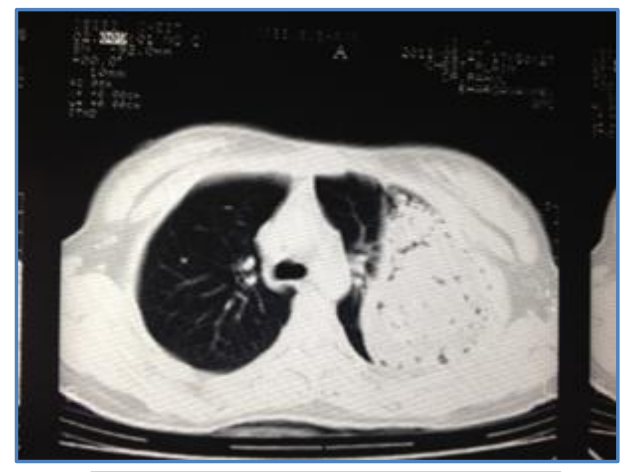

\section{Fig. 1: Hydatid cyst in} the left thorax

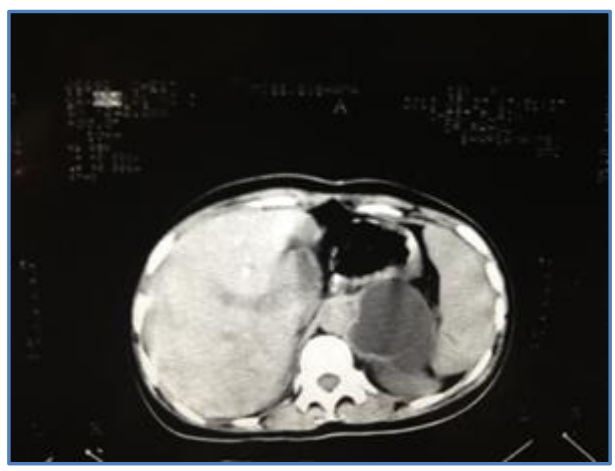

Fig. 2: Hydatid cyst extension via the hiatus 


\section{CASE REPORT}

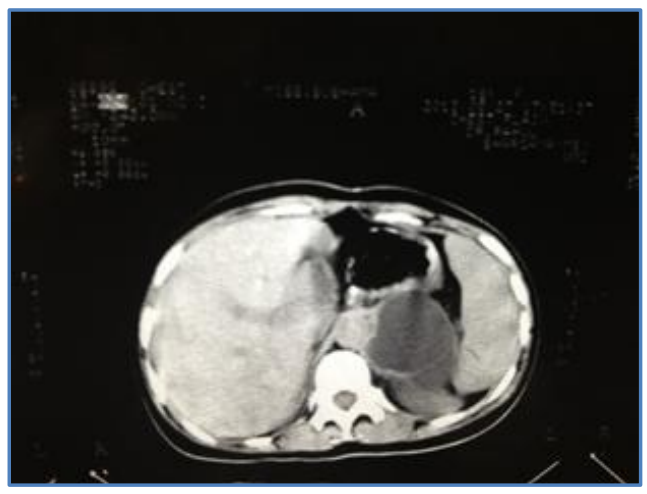

\section{Fig. 3: Hydatid cyst in the lesser} sac behind the stomach

\section{AUTHORS:}

1. Rahul Bhargava

2. Pradeep Soni

3. Atul Manoharrao Deshkar

\section{PARTICULARS OF CONTRIBUTORS:}

1. Assistant Professor, Department of Surgery, CIMS, Bilaspur CG India.

2. Associate Professor, Department of Surgery, CIMS, Bilaspur.

3. Associate Professor and HOD, Department of Physiology, CIMS, Bilaspur CG India.

\section{NAME ADDRESS EMAIL ID OF THE CORRESPONDING AUTHOR:}

Dr. Pradeep Soni,

Associate Professor and Consultant Surgeon,

Department of Surgery,

CIMS, Bilaspur.

Email: dratuldeshkar@gmail.com

Date of Submission: 20/05/2014.

Date of Peer Review: 23/05/2014.

Date of Acceptance: 26/05/2014.

Date of Publishing: 03/06/2014. 